Article

\title{
Application of CityDrain3 in Flood Simulation of Sponge Polders: A Case Study of Kunshan, China
}

\author{
Dingbing Wei ${ }^{1,2, *}$, Christian Urich ${ }^{2,3}$, Shuci Liu 4 (i) and Sheng Gu ${ }^{5, *}$ \\ 1 School of Civil Engineering, Southeast University, 2 Sipai Lou, Nanjing 210096, China \\ 2 Southeast University-Monash University Joint Research Centre for Water Sensitive Cities, \\ Suzhou 215123, China; christian.urich@monash.edu \\ 3 Department of Civil Engineering, Monash University, Clayton, VIC 3168, Australia \\ 4 Department of Infrastructure Engineering, The University of Melbourne, Parkville, VIC 3010, Australia; \\ shucil@student.unimelb.edu.au \\ 5 Kunshan Construct Engineering Quality Testing Center, Kunshan 215337, China \\ * $\quad$ Correspondence: kevin.wei@seu.edu.cn (D.W.); shenggu2018@163.com (S.G.); Tel.: +86-25-8379-3223 (D.W.)
}

Received: 2 March 2018; Accepted: 16 April 2018; Published: 19 April 2018

check for updates

\begin{abstract}
The selection of sponge city facilities (e.g., pump, storage tank, wetland, or bioretention pond) to mitigate urban floods has been a crucial issue in China. This study aims to develop a conceptual flood-simulation model, which can take into account the effects of such facilities of a sponge city. Taking Jiangpu polder in Kunshan City as a case study, CityDrain3 was implemented to develop a baseline model and another three sponge polder models (pump only, storage tank only, pump, and storage tank). A sensitivity analysis was carried out to guarantee the robustness of the newly developed model. In the model application part, firstly, one-hour rainfall scenarios with different return periods (2a, 5a, 10a, 20a, 50a, 100a, with 'a' referring to a year) were employed as inputs to the conceptual baseline model. The growing trend of flood depth (from $12.69 \mathrm{~mm}$ to $17.16 \mathrm{~mm}$ ) simulated by the baseline model under increased return periods (from 3a to 100a) demonstrated the feasibility of polder flood simulations using CityDrain3. Secondly, a one-hour rainfall scenario with a 10-year return period was employed on the baseline model and the three sponge polder models. The results showed that the effect rankings of the control strategies on the total flood volume, peak flow, flood yielding time, and the peak-flow occurrence time were comparable-combined strategies (pump and storage tank) > storage tank only $>$ pump only. The conceptual, and hydrological model developed in this study can serve as a simulation tool for implementing a real-time urban storm water drainage control system in the Jiangpu polder.
\end{abstract}

Keywords: CityDrain3 model; sponge city; polder; urban flood; sensitivity analysis

\section{Introduction}

A polder is defined as an area where catchments are surrounded by outer rivers [1]. In the Chinese Yangtze River Delta, there are many existing polders. A common feature of polders is that their elevations are lower than the water level in the surrounding outer river [2], resulting in high flooding risk during monsoon seasons. This is particularly an issue when a polder's storage capacity is insufficient, or a pumping station does not work properly. Flooding is a natural disaster that causes damage to human lives, as well as the economy [3]. However, compared with plain catchments [4-8], less effort has been made in mitigating the flooding risks of polders [9-11]. Therefore, investigating measures to control polder flooding problems is of a significant value.

Since 2013, the 'sponge city' concept has become a hot topic in China [12]. It was proposed as an effort to increase city resilience when dealing with storm water disasters. Similar to Best Management 
Practices (BMPs) [13], Low Impact Development (LID) [14], Water Sensitive Urban Design (WSUD) [15], and Sustainable Urban Design System (SUDS) [16], the Chinese sponge city concept has also adopted several facilities, such as wetlands, permeable pavements, ponds, bioretention ponds, storage tanks, and pumps. In Chinese sponge city practices, Jinan City has constructed a sponge city from four systems-water, road, grass, and architecture. Zhenjiang City has also implemented sponge city facilities with a focus on a river system [17]. These projects have demonstrated the effectiveness of the sponge city concept.

To evaluate the effectiveness of these sponge city strategies, special attention should be paid to the research related to urban storm water drainage systems. The urban storm water drainage system is an integrated infrastructure composed of various components (i.e., storm drainage, pumping stations, inner-rivers, out-rivers, and gates) [18]. To study the flooding performance of an urban area under a rainfall scenario, numerous software packages [19-21] have been developed to simulate urban storm water drainage systems.

Software packages used to simulate urban drainage systems can be classified into two typescommercial software and open source [22]. The commercial software is easy for engineers to implement and test. Some of the popular commercial software on the market include Mouse, Infoworks, Coral, Csoft, XPstorm, Hystem-Extran, and WEST [23,24]. In addition to commercial software, there are open-source tools which are sufficiently flexible to modify and add to the simulation algorithm, which in turn allows the integration of unique features for each drainage system. Two of the most commonly-used open-source tools are SWMM [22,25], and CityDrain [26,27]. The research presented in this paper investigates how CityDrain3 [28] can be implemented to simulate the flood volume of a polder in the Chinese Yangtze River Delta.

In this study, we introduced the concept of the sponge polder, and selected pumping stations and storage tanks as the two sponge facilities to control polder flood. Four control strategies (baseline, pumps only, storage tanks only, pumps, and storage tanks) were proposed to investigate the impact of different scenarios. This forms the basis for the later implementation of real-time controls on the urban storm water drainage system in the Jiangpu polder.

This paper is organized as follows. Section 2 provides a detailed explanation of the flow routing algorithm and the concept of integrated software CityDrain3. Section 3 shows the case study of the Jiangpu polder in China, using the simulation software CityDrain3. The last section draws some conclusions and provides the scope for future work.

\section{Modelling Framework}

\subsection{Flow Routing Models}

The urban drainage model is often implemented by using either a hydrological model or a hydrodynamic model. The hydrological model is a conceptualized model, which does not consider detailed information (e.g., detailed elevation data or sewer data). As a result, it is less dependent on computing time. However, the computational result is only appropriate where the influence of the sewer system can be neglected. The hydrodynamic model is often referred to as a detailed, physically-based model, which takes into account more detailed information of the urban catchments. This type of model can calculate the flow regime in the sewer pipes, including backwater effects at the expense of long computing times.

In our research, we aim to simulate the flood volume of the whole polder during specific rainfall scenarios. Because runoff is conveyed into the inner-river either by drainage sewer pipes or through catchment surfaces, we do not need to consider detailed urban drainage networks-thus selecting the hydrological model. Among all the hydrological models, we use CityDrain3, which is a well-known conceptual model adopting the Muskingum method to solve flow routing. 


\subsection{Modelling Software: CityDrain3}

The modelling framework applied in this study is CityDrain3, a conceptual integrated modelling tool for urban drainage systems, which uses the top-down modelling method [29]. The modelling tool, CityDrain3 was developed at the Unit of Environmental Engineering at the University of Innsbruck by Gregor Burger and his colleagues [28]. As an open source simulation tool, CityDrain3 allows users to implement modular designs to solve different research questions, while coding in the C++/Python environment.

In CityDrain3, every part of the urban drainage system (catchment, inner-river, storage facilities, pumping stations, outer-river, wastewater treatment plant, etc.) is described by a corresponding subsystem block. Each subsystem block is made up of in-ports, out-ports, underlying modelling algorithms, as well as physical properties like catchment area, impervious surface ratio, pumping station efficiency curve, river length, etc.

To initiate the calculation at any time step $n$, the data was imported from the previous $n-1$ time step and parameter data existing in the underlying blocks in CityDrain3 (i.e., catchment and inner-river physical properties). Each block uses its in-port data, as well as underlying physical properties of the research area to calculate the out-port values with the underlying modelling algorithms. The calculation began with the first rainfall input block, and the result was passed onto the downstream block, and so forth [29]. When the last block finished its calculation, the results of the $n^{\text {th }}$ time step were saved in the computer's memory, and the calculation for $n+1$ time step was initiated. Finally, the result calculated during the whole process was stored into a txt. file.

\section{Case Study of Jiangpu Polder}

\subsection{Site Description}

The model was applied at Jiangpu polder, Kunshan City, China (see Figure 1). Kunshan is a well-developed satellite city in the greater Suzhou region, located in the southeastern part of the Jiangsu province, adjacent to the Shanghai Municipality. The area where the case study was conducted is in the northwestern part of Kunshan city, and there were eight pumping stations, gates, and weirs. Moreover, the drainage system in this study area was a separate sewer system; storm water was conveyed to the nearest inner-river through stormwater pipes or flows into the inner-river in the form of catchment surface runoff. For the simulation of this site, four models were considered:

(1) Baseline model: The above described polder was assumed to have an absence of any storm water exchange (pumping stations) between the inner-river and outer-river. Meanwhile, there were no sponge facilities, such as storage tanks, wetlands, bioretention ponds, ponds, etc.

(2) Sponge polder model 1 (Pump only model): The pumping stations were located at the end of each inner-river to pump water from the inner-river to the outer-river, in case of the possibility of flooding. Water in the outer-river of Jiangpu polder then flowed into the Yangtze River and finally flowed into the East China Sea. According to the pumping control strategy, the pumping was started when the water level of the inner-river became higher than $2.6 \mathrm{~m}$ and the pumping was stopped when the water level of the inner-river became lower than $2.2 \mathrm{~m}$.

(3) Sponge polder model 2 (storage tank only model): Storage tanks were located at the downstream point of each sub-catchment. Whenever there was sub-catchment surface runoff over the storage tank, a part of the runoff flowed into the storage tank at a fixed flow speed.

(4) Sponge polder model 3 (pump and storage tank): Pumping stations and storage tanks worked at the same time when their working conditions were triggered.

\subsection{Application and Data Analysis}

In this study, the storm water system of Jiangpu polder was stimulated to calculate the flood volume of the whole area. Different catchments were divided into several parts, with the runoff from each part of the catchment draining into the inner-river section according to the terrain. 
The Muskingum model was implemented as the underlying algorithm in the catchment and inner-river blocks. The system simulation scheme is represented in Figure 2.

As evident from Figure 2, when rain fell onto the catchment area, through the Muskingum algorithm, the flow routing was calculated to generate a runoff that flowed into the inner-river section. Usually, the runoff from the several catchments drained into the same inner-river section. The pumping station was installed at each end of an inner-river section to pump water from the inner-river to outer-river. The rainfall and pump working situation were regarded as the input to the system, with the water level of the whole inner-river system being treated as the final output (which could later be used to calculate the flood volume of the whole system).

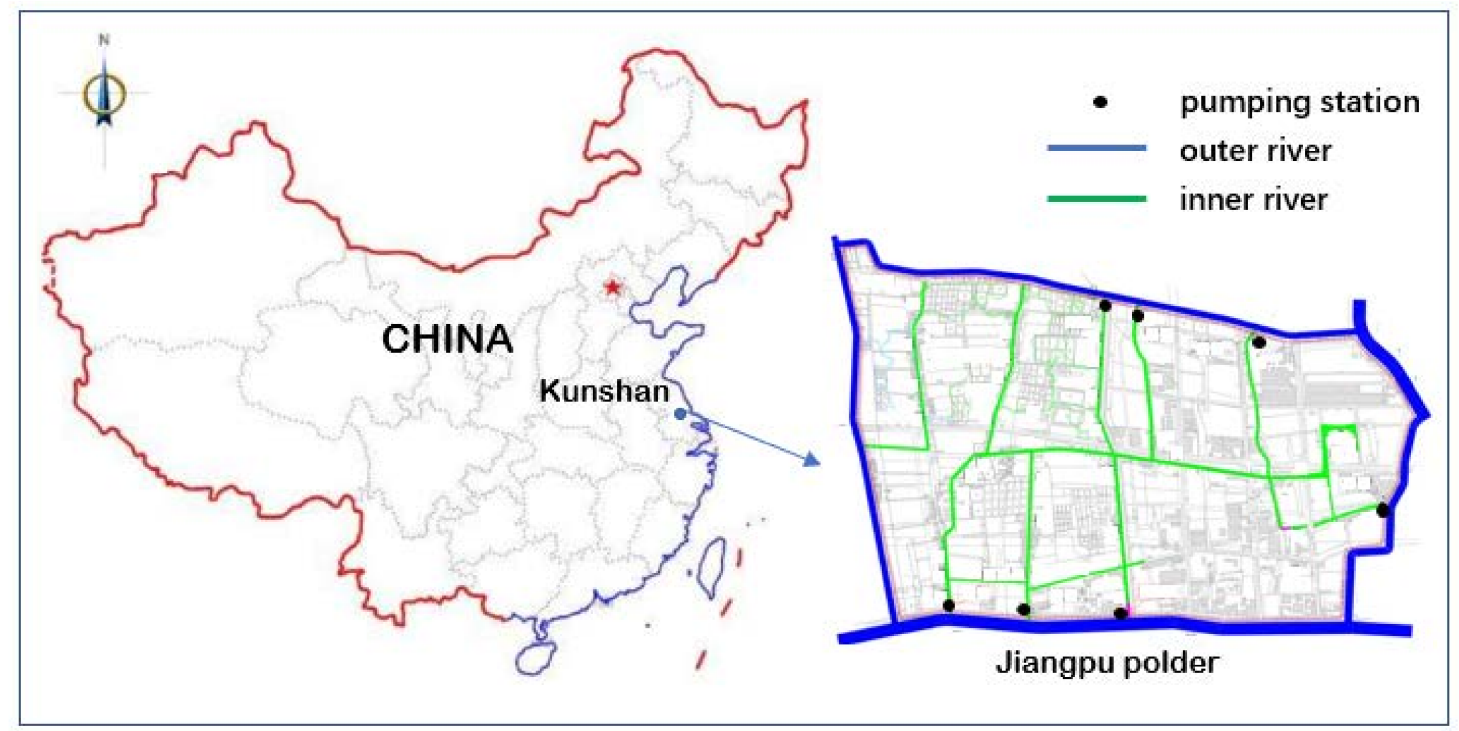

Figure 1. Simulation site: Jiangpu polder of Kunshan City.

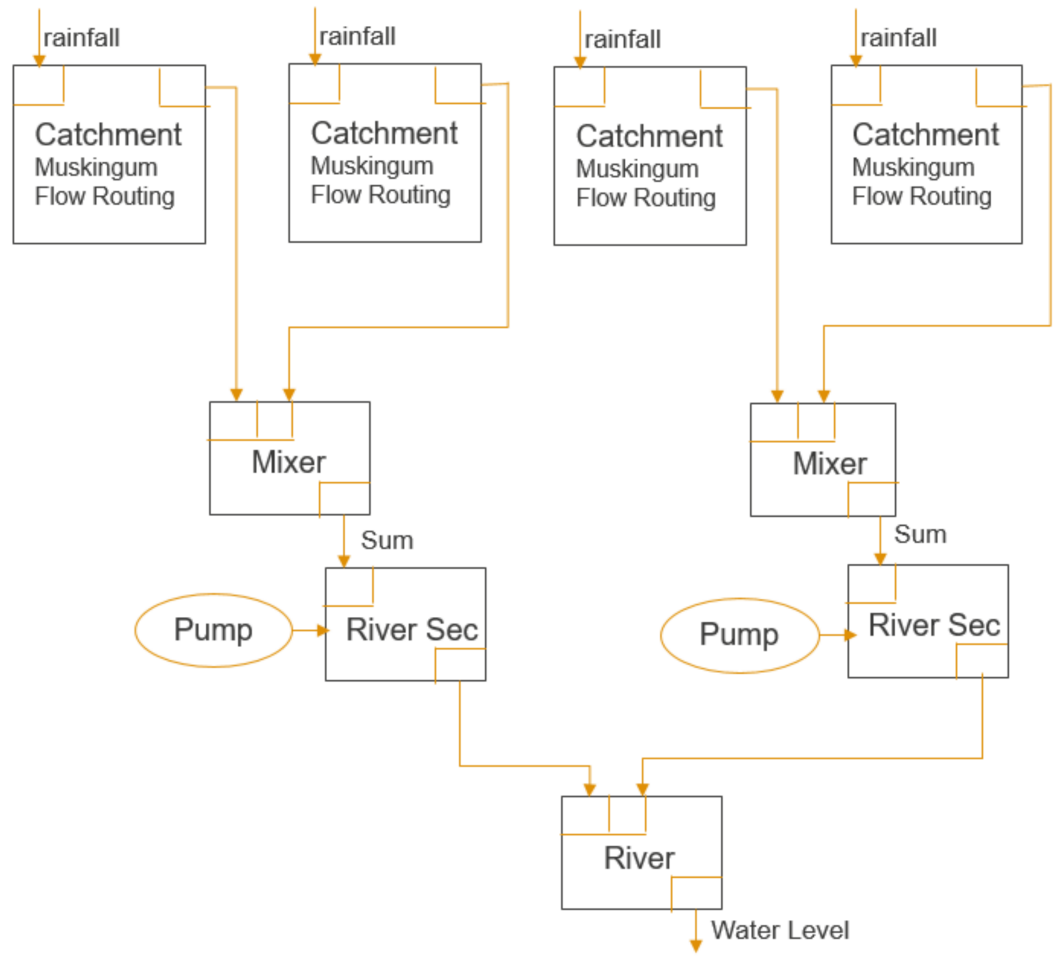

Figure 2. Jiangpu polder system simulation scheme. 


\subsubsection{Rainfall Data}

Rainfall design is an important basis for urban drainage system design and sponge city construction. If the rainfall data far exceed reality, this could result in the construction of a massive drainage system and significant economic burden.

The Chicago Method is widely used in China to design the rainfall process on the basis of the rainstorm intensity equation. The Kunshan government implemented the Chicago Method and deduced the rainstorm intensity equation in 2017 [30] as:

$$
i=\frac{9.5336 \times\left(1+0.5917 \times \log T_{M}\right)}{(t+5.9828)^{0.6383}}
$$

The rainfall process hydrograph can be described in Equations (5) and (6),

$$
\begin{gathered}
i_{\text {before }}=\frac{A \times\left(1+c \times \log T_{M}\right)\left[\frac{1-n}{r} \times t_{1}+b\right]}{\left(\frac{t_{1}}{r}+b\right)^{n+1}} \\
i_{\text {after }}=\frac{A \times\left(1+c \times \log T_{M}\right)\left[\frac{1-n}{1-r} \times t_{2}+b\right]}{\left(\frac{t_{2}}{1-r}+b\right)^{n+1}}
\end{gathered}
$$

where $T_{M}, A, b, n$ are the parameters in the rainstorm intensity equation, $b=5.9828, n=0.6383 ; r$ is the peak coefficient which expresses the ratio between peak flow time point and rain duration. In the Kunshan case, $r=0.438 ; t_{1}$ and $t_{2}$ are the time space before and after peak flow time point; $i_{\text {before }}$ and $i_{\text {after }}$ describe the rainfall intensity before and after peak flow, respectively.

In this study, rainfall duration time was set as one hour, and rainfall return period was set as, 2a, 5a, 10a, 20a, 50a, and 100a. The rainfall hydrograph can be referred to in Figure 3.

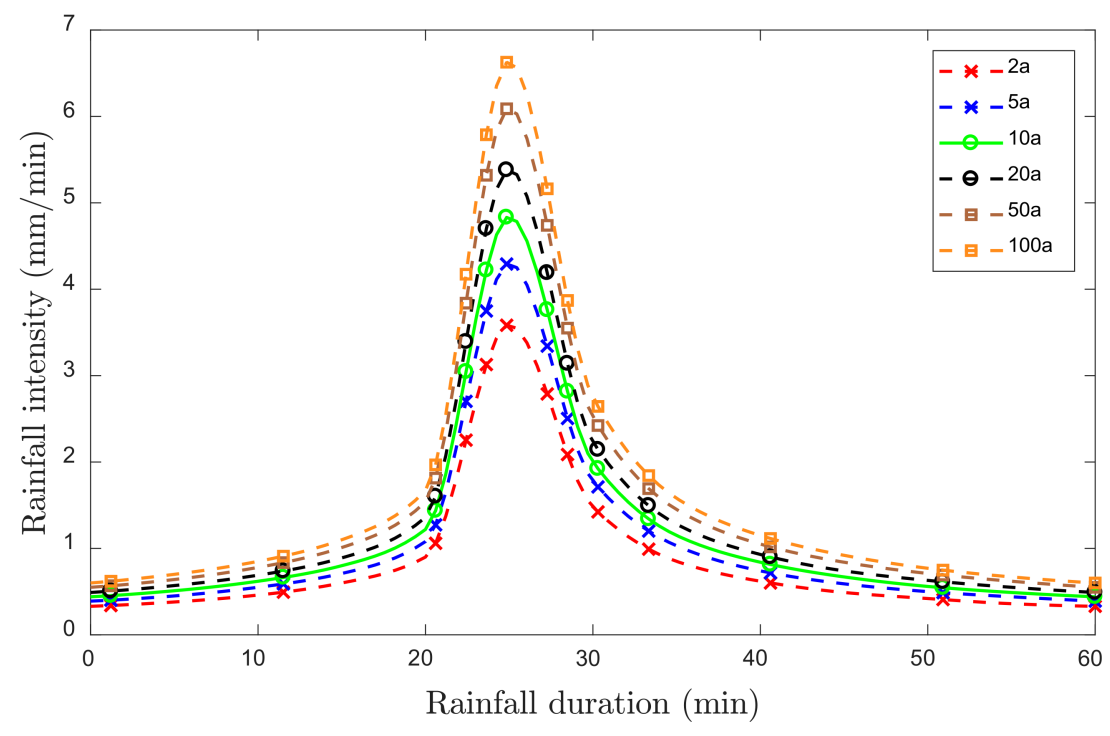

Figure 3. One-hour rainfall hydrograph with different return periods.

\subsubsection{Sub-Catchment Physical Properties}

Sub-catchment parameters were fixed according to the physical properties of the Jiangpu polder area. The area of each sub-catchment was measured with an electronic ruler on the map. The runoff coefficient was decided as the Chinese government's statistical result, with forest park areas as 0.15 , urban areas with intensive buildings as 0.55 , and urban areas with sparse buildings as 0.4 . Data from 
the pumping station were also very important, which gave detailed information of each pumping station $\left(\right.$ Table 1) (Note: $\mathrm{WL}_{\mathrm{ON}}=$ water level for pump start; $\mathrm{WL}_{\mathrm{OFF}}=$ water level for pump stop).

Table 1. Pumping station data.

\begin{tabular}{ccccc}
\hline ID & Name & $\mathbf{Q}\left(\mathbf{m}^{3} / \mathbf{s}\right)$ & $\mathbf{W L}_{\mathbf{O N}}(\mathbf{m})$ & $\mathbf{W L}_{\mathbf{O F F}}(\mathbf{m})$ \\
\hline 1 & GONGYUAN & 4.8 & & \\
2 & DONGDANG & 3.2 & & \\
3 & HONGQIAO & 2.85 & & \\
4 & YUEHE & 6.5 & 2.6 & \\
5 & SICHANGGANG & 3.0 & & \\
6 & BAITA & 3.2 & & \\
7 & GONGQING & 3.7 & & \\
8 & XIDANG & 7.0 & & \\
\hline
\end{tabular}

\subsection{Results and Discussion}

\subsubsection{Sensitivity Analysis}

The sensitivity analysis was to understand how each parameter affected the simulation output, and to assess which parameters should be concentrated on. The sensitivity analysis techniques have been developed and categorized into different classes, including derivative analysis, algebraic analysis of model equations, sparse sampling, variance decomposition, Fourier analysis, binary classification, and many more. The first two kinds of sensitivity analysis techniques could provide detailed insight, while sampling-based sensitivity analysis techniques could handle more complex models to obtain the necessary information at a relatively low computational cost [31].

In this study, we implemented two steps in sensitivity analysis techniques. In the first step, we calculated the total flood volume using different parameter values (i.e., changed only one parameter at one time), demonstrating how sensitive the model performance is to the change in individual parameters. In the second step, a traditional sensitivity analysis technique-the Morris screening method [32] — was adopted to further evaluate the impact of the parameter on the model output.

Preliminary Calculation for Sensitivity Analysis

In the above conceptual model, several parameters were considered in the sensitivity analysis. From Figure 2, the polder is substituted by several blocks, e.g., rainfall block, catchment block, river block, mixer block, and pump block. Through experience screening, the parameters that should be included in the sensitivity analysis are highlighted in the catchment, and river blocks, outlined in Table 2.

Table 2. Screening parameters of sensitivity analysis.

\begin{tabular}{cccc}
\hline Model Components & Parameter & Value Range & Best Fit \\
\hline \multirow{3}{*}{ Catchment } & K [s] & $100 \sim 300$, delta 50 & 300 \\
& N [-] & $3 \sim 15$, delta 3 & 3 \\
& X [-] & $0 \sim 0.5$, delta 0.1 & 0 \\
Kiver & K [s] & $100 \sim 300$, delta 50 & 300 \\
& N [-] & $7 \sim 15$, delta 2 & 11 \\
& X [-] & $0 \sim 0.5$, delta 0.1 & 0 \\
\hline
\end{tabular}

Figure 4 shows the sensitivity analysis result of the Muskingum parameters $K, N, X$ in the catchment and river blocks. Results were calculated by running the CityDrain3 models manually. In comparison, we preliminarily find that $C N, R K, R N$ and $R X$ are the sensitive factors to the output (Note: $\mathrm{CK}=$ Catchment $\mathrm{K} ; \mathrm{CN}=$ Catchment $\mathrm{N} ; \mathrm{CX}=$ Catchment $\mathrm{X} ; \mathrm{RK}=$ River $\mathrm{K}$; $\mathrm{RN}=\mathrm{River} \mathrm{N}$; $\mathrm{RX}=$ River $\mathrm{X} ; \mathrm{FV}=$ Flood Volume). 


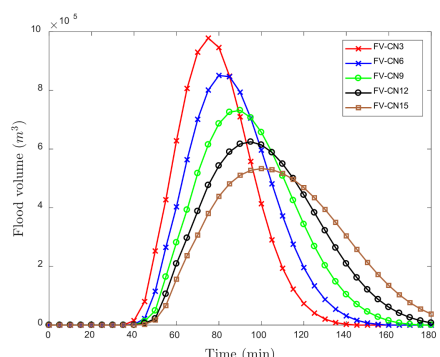

(a)

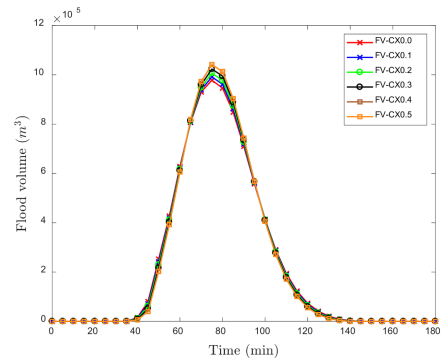

(c)

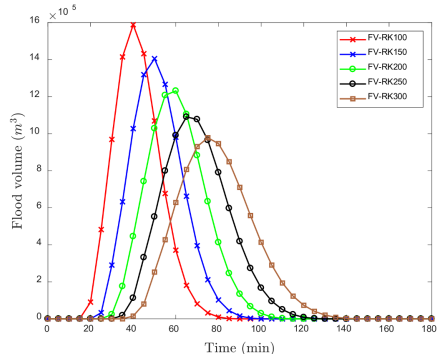

(e)

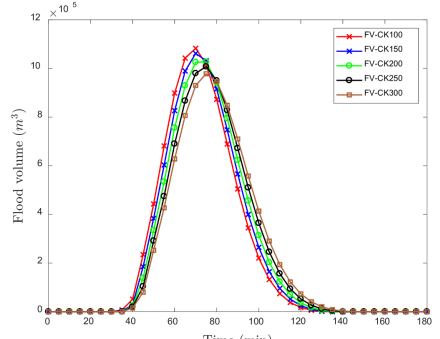

(b)

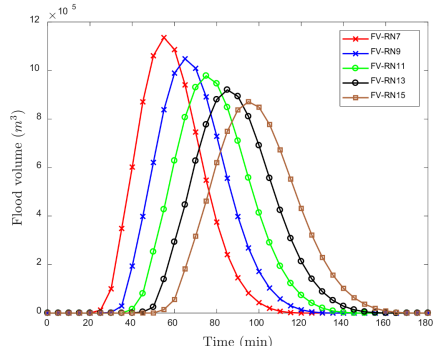

(d)

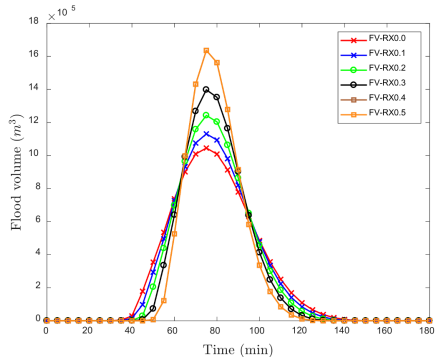

(f)

Figure 4. Preliminary sensitivity analysis result of parameters in the catchment and river blocks: (a) catchment $\mathrm{K},(\mathbf{b})$ catchment $\mathrm{N},(\mathbf{c})$ catchment $\mathrm{X},(\mathbf{d})$ river $\mathrm{K},(\mathbf{e})$ river $\mathrm{N}$, and (f) river $\mathrm{X}$.

The Morris Screening Method for Sensitivity Analysis

The Morris screening [33] proposed an elementary effects method to assess which factors may have (a) negligible; (b) linear; (c) nonlinear interactions with other factors [34]. After implementing a number of model runs, the influence of parameters on output can be ranked. This will discard those lower-ranked parameters to avoid expensive computational time cost and allow researchers to focus on the parameters that have an obvious effect on output [31].

In the next step, the Morris screening method was applied to different parameters in the catchment and river blocks (Table 3 and Figure 5). The results of sensitivity measures ( $\mu$ and $\sigma$ ) for different parameters influencing output (total flood volume of the Jiangpu polder) (Table 3) and the graphical results of each parameter in Morris screening analysis (Figure 5) are represented. As we can see from Table 3 and Figure 5, and the preliminary findings (Figure 4), CN showed the most sensitive effect on the overall flood volume result. Therefore, special attention was paid to the study of $C N$. After comparing with the overall flood volume when $N$ equals $3-15$, it was found that when $N=3$, the overall flood volume was equivalent to the one that was calculated with different values of $C K$ and $C X$. 
Table 3. Morris screening sensitivity analysis result of total-flood volume.

\begin{tabular}{cccc}
\hline Parameter & $\boldsymbol{\mu}$ (Mean) & $\sigma$ (Sigma) & $\sigma / \mu$ \\
\hline CK & -2458.263608 & 4498.145451 & -1.83 \\
CN & $14,947.945884$ & $456,305.8701$ & 30.53 \\
CX & $-46,902.31404$ & $39,686.59956$ & -0.85 \\
RK & -2314.093176 & 1529.955954 & -0.66 \\
RN & $-22,624.78659$ & $15,590.01461$ & -0.69 \\
RX & -103.258607 & 41.1759731 & -0.40 \\
\hline
\end{tabular}

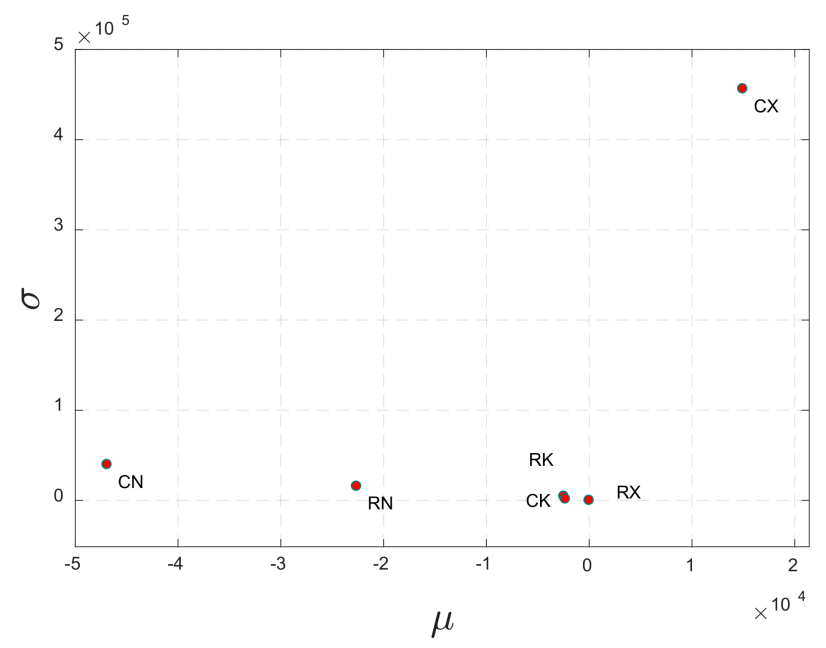

Figure 5. Morris sensitivity analysis result of Muskingum parameters in Jiangpu polder model.

\subsubsection{Model Calibration}

In order to develop a conceptual model that is sufficiently accurate in simulating the real urban drainage system, a calibration of sub-catchment physical parameters and Muskingum parameters $K, N$ and $X$ in the catchment blocks, as well as in the river blocks in the future should be employed. The results of the Nash-Sutcliffe efficiency coefficient (NSE) [35] should show that the conceptual model can represent the real circumstance well and the conceptual model developed within this procedure is acceptable.

However, in this research, the aim was to compare the effects of different control strategies (baseline, with pump only, with storage tank only, and with both pump and storage tank). The model calibration work will be carried out in the near future as an extension of this work.

\subsubsection{Application of the Model}

Storms with different return periods were designed as inputs into the developed model to study the effects of sponge polder facilities. In the first step, a preliminary application of several rainfall scenarios was employed to evaluate the relationship between rainfall depth and flood depth. Then, a comparison of the baseline and sponge polder models was carried out to study the effects of different sponge facilities.

Flood Calculation under Different Rainfall Return Periods

For the application of the earlier developed model, precipitation of one-hour duration with different return periods (2a, 5a, 10a, 20a, 50a, and 100a) was implemented as an input into the baseline model. After flow routing with the CityDrain3 model, the rainfall depth and flood depth under every scenario could be compared (Figure 6). 


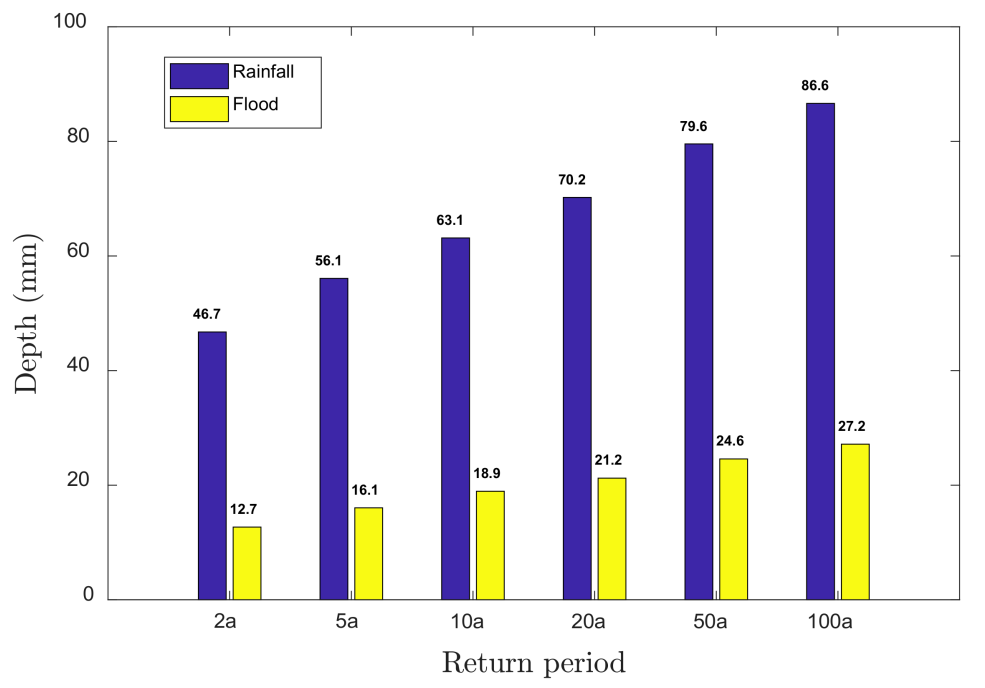

Figure 6. Simulated flood depth in Jiangpu polder with different return period precipitations.

When the rainfall duration was one hour, with return periods of $2 \mathrm{a}$ to $100 \mathrm{a}$, the total rainfall depth ranged from $46.7 \mathrm{~mm}$ to $86.6 \mathrm{~mm}$ (Figure 6). The calculated flood depth ranged from $12.7 \mathrm{~mm}$ to $27.2 \mathrm{~mm}$. The growing trend of flood depth under increased precipitation showed the feasibility of polder flood simulation with CityDrain3. This was the basis for the next comparison of baseline and sponge polder models.

Because the developed model was a conceptual system, the flood depth shown in Figure 6 was the average value of the whole polder area. In practice, different sub-catchments have different elevations, so the flood volume would flow to the sub-catchment areas with low elevation. This causes severe flood problems, including loss of human life and economic damage.

Comparison of Baseline and Sponge Polder Models

To investigate the effects of different sponge polder facilities, a one-hour rainfall with return period of 10 years was employed in the developed baseline model and the three sponge polder models. The simulation results are shown in Figure 7, with detailed information listed in Table 4.

Results (Figure 7) indicated that the pump and storage tank could lead to a reduction in total flood volume, flood yielding time, peak flow, and peak-flow occurrence time. Moreover, the effects of combined strategies (pump and storage tank) showed a linear relationship with the effect of each individual control strategy (pump only or storage tank only). The reason was that the both of the individual control strategies chosen in this research had a linear effect on the water volume. It should be noted that there was no control strategy with the infiltration effect in the model.

The effect of control strategies on total flood volume was ranked as-combined strategies (pump and storage tank) $>$ storage tank only $>$ pump only (Table 4 and Figure 7). The effect on peak flow was ranked as-combined strategies (pump and storage tank) $>$ storage tank only $>$ pump only. The effect on the flood yielding time was ranked as-combined strategies (pump and storage tank) > storage tank only > pump only. The effect on the peak-flow occurrence time was ranked as: Combined strategies (pump and storage tank) $>$ storage tank only $>$ pump only. The results were attributed to the linear relationship of the two individual control strategies chosen in this research. 


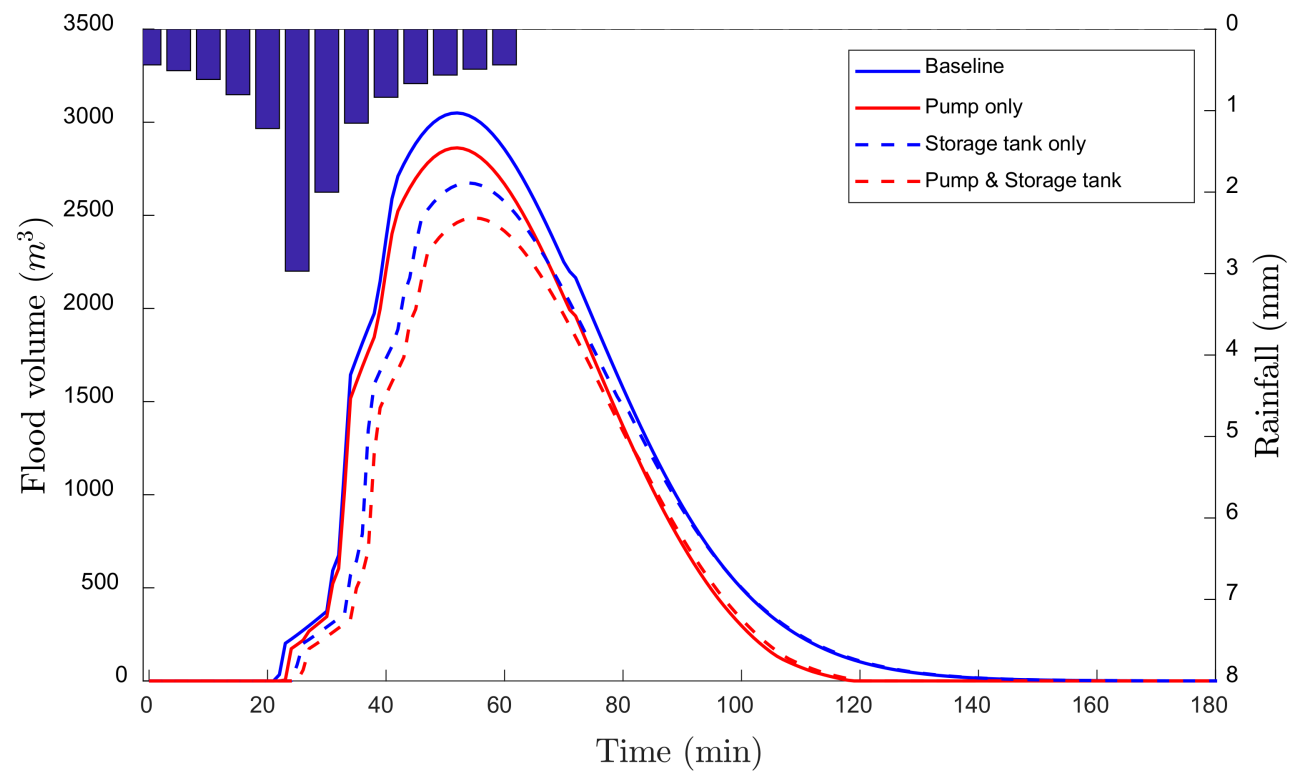

Figure 7. Comparison of total flood volume in the Jiangpu polder area during a rainfall with one-hour duration and 10-year return period under different flood control strategies.

Table 4. Detailed simulation result of polder area under different control strategies.

\begin{tabular}{ccccc}
\hline Type of Models & Baseline & Pump Only & $\begin{array}{c}\text { Storage Tank } \\
\text { Only }\end{array}$ & $\begin{array}{c}\text { Combination of Pump } \\
\text { and Storage Tank }\end{array}$ \\
\hline Total rainfall $\left(\mathrm{m}^{3}\right)$ & & & 496,005 & \\
Total flood volume $\left(\mathrm{m}^{3}\right)$ & 146,235 & 128,533 & 126,580 & 108,913 \\
Reduction of flood volume $\left(\mathrm{m}^{3}\right)$ & & 17,702 & 19,655 & 37,322 \\
Reduction percentage & & $12.1 \%$ & $13.4 \%$ & $25.5 \%$ \\
Peak flow $\left(\mathrm{m}^{3} / \mathrm{min}^{2}\right.$ & 3050 & 2862 & 2674 & 2486 \\
Reduction of peak flow $\left(\mathrm{m}^{3} / \mathrm{min}\right)$ & & 188 & 376 & 564 \\
Reduction percentage & & $6.16 \%$ & $12.33 \%$ & $18.5 \%$ \\
Flood yielding time $(\mathrm{min})$ & 22 & 23 & 25 & 26 \\
Reduction of Flood yielding time (min) & & 1 & 3 & 5 \\
Peak-flow occurrence time (min) & 52 & 52 & 54 & 55 \\
Reduction of Peak-flow occurrence time (min) & & 0 & 2 & 3 \\
\hline
\end{tabular}

\section{Conclusions and Future Work}

In this paper, a conceptual flood-simulation model was developed using CityDrain3. The developed model was applied on a storm water management program at Jiangpu polder, Kunshan, China. The baseline model was first implemented to calculate flood depth under different rainfall scenarios. Later, the baseline model and three sponge polder models were used to estimate the storm water flood result. According to the results and discussions, the following key findings could be concluded:

(1) CityDrain3 can be applied to conceptualize the urban flood performance of polder areas in the Yangtze River Delta area in China. The CityDrain3 model developed in this paper was set up according to the Jiangpu polder land surface information. Sensitivity analysis showed the robustness of the key parameters in each sub-catchment of the model. A hydrological model was used to calculate the flow routing in the polder system.

(2) Preliminary application of the developed baseline model was used to calculate flood depth of the Jiangpu polder under one-hour rainfall with return periods of 2a, 5a, 10a, 20a, 50a, and 100a. It is apparent that the growing trend of flood depth under increased precipitation showed the feasibility of the polder flood simulation using CityDrain3. 
(3) A comparative study of the strategies was used to investigate the flood results of the baseline model and three sponge polder models. The effect of control strategies on total flood volume was ranked as—combined strategies $(25.5 \%)>$ storage tank only $(13.4 \%)>$ pump only $(12.1 \%)$. The effect on peak flow was ranked as-combined strategies $(18.5 \%)>$ storage tank only $(12.33 \%)>$ pump only $(6.16 \%)$. The effect on the flood yielding time was ranked as-combined strategies $(4 \mathrm{~min})>$ storage tank only $(3 \mathrm{~min})>$ pump only $(1 \mathrm{~min})$. The effect on the peak-flow occurrence time was ranked as-combined strategies $(3 \mathrm{~min})>$ storage tank only $(2 \mathrm{~min})>$ pump only $(0 \mathrm{~min})$.

(4) The results obtained using the CityDrain 3 model can help the engineers and stakeholders to understand and select among the sponge polder facilities.

For future research, there should be more blocks coded to represent sponge polder facilities, e.g., wetlands, bioretention ponds, and grassed swales. This would give CityDrain3 model the ability to realize the real-time control of a polder flood.

Further, there should be flow meters and water-level sensors installed to capture in-situ measurements. The practical measurement data could then be used to verify the developed simulation model. Selecting the optimal control strategy and realizing the real-time control of urban floods could be the main extension of the model developed in this paper.

Acknowledgments: This study was funded by the National key Technologies R\&D Program (No. 2015BAL02B05), the Priority Academic Program Development of Jiangsu Higher Education Institutions (No. 1105007002), the Fundamental Research Funds for Southeast University (No. KYLX15_0093) and China Scholarship Council.

Author Contributions: Christian Urich conceived and designed the study topic, imported the simulation software CityDrain3 and did preliminary research with this software; Dingbing Wei chose the case study area, did the main simulation work and analyzed the data; Shuci Liu checked the data and drew figures; Sheng Gu contributed in writing the paper.

Conflicts of Interest: The authors declare no conflicts of interest.

\section{References}

1. Deng, Y. Hydrological characteristics analysis and water exchange modelling for polders in plain river network area. In College of Geographical Science; Nanjing Normal University: Nanjing, China, 2014. (In Chinese)

2. Jingsen, L. Optimization methods for conventional scheduling of drainage pumps in plain polders. In Agricultural Soil and Water Engineering; Yangzhou University: Yangzhou, China, 2014. (In Chinese)

3. Vermuyten, E.; van den Zegel, B.; Wolfs, V.; Meert, P.; Willems, P. Real-time flood control by means of an improved MPC-GA algorithm and a fast conceptual river model for the demer basin in Belgium. In Proceedings of the 6th International Conference on Flood Managament, São Paulo, Brazil, 16-18 September 2014.

4. Maksimović, Č.; Prodanović, D.; Boonya-Aroonnet, S.; Leitao, J.P.; Djordjević, S.; Allitt, R. Overland flow and pathway analysis for modelling of urban pluvial flooding. J. Hydraul. Res. 2009, 47, 512-523. [CrossRef]

5. Vezzaro, L.; Grum, M. A generalised Dynamic Overflow Risk Assessment (DORA) for Real Time Control of urban drainage systems. J. Hydrol. 2014, 515, 292-303. [CrossRef]

6. Qin, H.-P.; Li, Z.-X.; Fu, G. The effects of low impact development on urban flooding under different rainfall characteristics. J. Environ. Manag. 2013, 129, 577-585. [CrossRef] [PubMed]

7. Chang, F.-J.; Chen, P.-A.; Lu, Y.-R.; Huang, E.; Chang, K.-Y. Real-time multi-step-ahead water level forecasting by recurrent neural networks for urban flood control. J. Hydrol. 2014, 517, 836-846. [CrossRef]

8. Domingo, N.S.; Refsgaard, A.; Mark, O.; Paludan, B. Flood analysis in mixed-urban areas reflecting interactions with the complete water cycle through coupled hydrologic-hydraulic modelling. Water Sci. Technol. 2010, 62, 1386-1392. [CrossRef] [PubMed]

9. Wei, H. Study on simulation and operation of flooding prevention system in plain river-net region. In Hydrology and Water Resources; Hohai University: Nanjing, China, 2007. (In Chinese)

10. Dazhou, $X$. Research and implemention of automation and dispatch management system of pumping group station in Langxia polder areas. In Agricultural Automation and Electrization; Yangzhou University: Yangzhou, China, 2017. (In Chinese) 
11. Jianye, X. Effect of polder management methods on flooding prevention. In Agricultural Water and Soild Engineering; Yangzhou University: Yangzhou, China, 2009. (In Chinese)

12. Li, X.; Li, J.; Fang, X.; Gong, Y.; Wang, W. Case Studies of the Sponge City Program in China. In Proceedings of the World Environmental and Water Resources Congress 2016, West Palm Beach, FL, USA, 22-26 May 2016.

13. Villarreal, E.L.; Semadeni-Davies, A.; Bengtsson, L. Inner city stormwater control using a combination of best management practices. Ecol. Eng. 2004, 22, 279-298. [CrossRef]

14. Dietz, M.E. Low impact development practices: A review of current research and recommendations for future directions. Water Air Soil Pollut. 2007, 186, 351-363. [CrossRef]

15. Wong, T.H. An overview of water sensitive urban design practices in Australia. Water Pract. Technol. 2006, 1, wpt2006018. [CrossRef]

16. Fletcher, T.D.; Shuster, W.; Hunt, W.F.; Ashley, R.; Butler, D.; Arthur, S.; Trowsdale, S.; Barraud, S.; Semadeni-Davies, A.; Bertrand-Krajewski, J.-L. SUDS, LID, BMPs, WSUD and more-The evolution and application of terminology surrounding urban drainage. Urban Water J. 2015, 12, 525-542. [CrossRef]

17. Cui, G.; Zhang, Q.; Zhan, Z.; Chen, Y. Research progress and discussion of sponge city construction. Water Resour. Prot. 2016, 32, 1-4. (In Chinese)

18. Bach, P.M.; Rauch, W.; Mikkelsen, P.S.; McCarthy, D.T.; Deletic, A. A critical review of integrated urban water modelling-Urban drainage and beyond. Environ. Mode. Softw. 2014, 54, 88-107. [CrossRef]

19. Figueras, J.; Cembrano, G.; Puig, V.; Quevedo, J.; Salamero, M.; Martí, J. Coral off-line: An object-oriented tool for optimal control of sewer networks. In Proceedings of the 2002 IEEE International Symposium on Computer Aided Control System Design, Glasgow, UK, 20 September 2002.

20. Burger, G.; Sitzenfrei, R.; Kleidorfer, M.; Rauch, W. Parallel flow routing in SWMM 5. Environ. Model. Softw. 2014, 53, 27-34. [CrossRef]

21. Puig, V.; Cembrano, G.; Romera, J.; Quevedo, J.; Aznar, B.; Ramon, G.; Cabot, J. Predictive optimal control of sewer networks using CORAL tool: Application to Riera Blanca catchment in Barcelona. Water Sci. Technol. 2009, 60, 869-878. [CrossRef] [PubMed]

22. Riaño-Briceño, G.; Barreiro-Gomez, J.; Ramirez-Jaime, A.; Quijano, N.; Ocampo-Martinez, C. MatSWMM-An open-source toolbox for designing real-time control of urban drainage systems. Environ. Model. Softw. 2016, 83, 143-154. [CrossRef]

23. García, L.; Barreiro-Gomez, J.; Escobar, E.; Téllez, D.; Quijano, N.; Ocampo-Martinez, C. Modeling and real-time control of urban drainage systems: A review. Adv. Water Resour. 2015, 85, 120-132. [CrossRef]

24. Amdisen, L.K.; Gavranovic, N.; Yde, L. Model-based control-a hydroinformatics approach to real-time control of urban drainage systems. J. Hydraul. Res. 1994, 32, 35-43. [CrossRef]

25. Muschalla, D.; Vallet, B.; Anctil, F.; Lessard, P.; Pelletier, G.; Vanrolleghem, P.A. Ecohydraulic-driven real-time control of stormwater basins. J. Hydrol. 2014, 511, 82-91. [CrossRef]

26. Achleitner, S.; Möderl, M.; Rauch, W. CITY DRAIN@-An open source approach for simulation of integrated urban drainage systems. Environ. Model. Softw. 2007, 22, 1184-1195. [CrossRef]

27. Achleitner, S. Modular Conceptual Modelling in Urban Drainage Development and Application of City Drain; IUP-Innsbruck University Press: Innsbruck, Austria, 2008.

28. Burger, G.; Bach, P.M.; Urich, C.; Leonhardt, G.; Kleidorfer, M.; Rauch, W. Designing and implementing a multi-core capable integrated urban drainage modelling Toolkit: Lessons from CityDrain3. Adv. Eng. Softw. 2016, 100, 277-289. [CrossRef]

29. Forster, C. Urban Water Cycle Modelling with CityDrain3-Water Balance Improvements and a Demonstration Case Study. In Institute for Urban Water Management; Dresden University of Technology: Dresden, Germany, 2016.

30. Raoming, S.; Shao, D.; Jin, J.; Zhu, H. Study on Rainstorm Intensity Equation and Design of Rainstorm in Kunshan City; H.W.W.S.A.D. Company: Kunshan, China, 2016.

31. Norton, J. An introduction to sensitivity assessment of simulation models. Environ. Model. Softw. 2015, 69, 166-174. [CrossRef]

32. Ruano, M.; Ribes, J.; Ferrer, J.; Sin, G. Application of the Morris method for screening the influential parameters of fuzzy controllers applied to wastewater treatment plants. Water Sci. Technol. 2011, 63, 2199-2206. [CrossRef] [PubMed]

33. Morris, M.D. Factorial sampling plans for preliminary computational experiments. Technometrics 1991, 33, 161-174. [CrossRef] 
34. Campolongo, F.; Cariboni, J.; Saltelli, A. An effective screening design for sensitivity analysis of large models. Environ. Model. Softw. 2007, 22, 1509-1518. [CrossRef]

35. Hwang, S.H.; Ham, D.H.; Kim, J.H. A new measure for assessing the efficiency of hydrological data-driven forecasting models. Hydrol. Sci. J. 2012, 57, 1257-1274. [CrossRef]

(C) 2018 by the authors. Licensee MDPI, Basel, Switzerland. This article is an open access article distributed under the terms and conditions of the Creative Commons Attribution (CC BY) license (http://creativecommons.org/licenses/by/4.0/). 